a stroke of about 32 per minute the mechanical efficiency is apparently near its maximum.

An enormous amount of work has to be done in propelling a boat at speeds like Io to I 2 miles per hour. According to Henderson, each member of the crew of an eight-oar boat must exert about 0.6 of a horse-power. Clearly, if this enormous amount of external work is to be done, it must be accomplished by working under efficient conditions: those conditions necessitate a stroke of a particular frequency; only when the race is very short is it permissible, in order to obtain a greater output, to work less efficiently by adopting a more rapid stroke. The stroke may rise to 40 per minute for a short distance : in such an effort the oxygen debt is accumulating rapidly and exhaustion will soon set in. The amount of work, moreover, will not be proportionately greater, probably only slightly greater, than at the lower frequency. The conditions which determine the speed of movement, the "viscous-elastic" properties of muscle, are what ultimately decide the length of the oars and the speed of movement in a racing-boat.

\section{Wastefulness of High Speeds.}

This last discussion leads us to the question of what determines the great wastefulness of the higher speeds. Why, returning to Fig. 2, does a speed of 280 steps per minute require 24 litres of oxygen per minute, while a speed of 240 steps per minute requires only eight litres of oxygen? The answer depends upon the variation of external work with speed of muscular movement. In a series of recent papers it has been shown that in a maximal muscular movement the external work decreases in a linear manner as the speed of shortening increases. At sufficiently high speeds of shortening no external work at all can be performed.

In most of these athletic exercises, apart from the case of rowing, a large proportion of the mechanical work is used in overcoming the viscous resistance of the muscles themselves. At high speeds of running only a small fraction of the mechanical energy of the muscles is available to propel the body, once the initial inertia has been overcome. The work is absorbed by internal friction, or by those molecular changes which, when the muscle is shortening rapidly, cause its tension to fall off. When working against an external resistance, as in rowing, there is an optimum speed. If an effort is to be long continued it must be made at a speed not far from the optimum. When, however, the whole of the resistance to movement is internal, as in running, there is no optimum speed : the expense of the movement increases continually as the speed goes up; the faster we move, the greater relatively the price: our footsteps are dogged by the viscous-elastic properties of muscle, which prevent us from moving too fast, which save us from breaking ourselves while we are attempting to break a record.

\section{JUMPING.}

One final point may be worthy of mention-this time connected with high-jumping and long-jumping. Recently I made a series of observations, with a stopwatch reading to 0.02 second, of the times occupied by a number of high-jumpers from the moment they left the ground to the moment they reached the ground again. With men jumping about 5 feet the time averaged about 0.80 second. Calculating from the formula

$$
\mathrm{S}=\frac{1}{2} g t^{2}
$$

where $t$ is half the total time of flight, the distance through which the centre of gravity of the body was raised must have been about $2 \cdot 5$ feet. The men competing must have had an original height of their centre of gravity of about 2.9 feet. Thus, in the high-jump, their centres of gravity went about 5.4 feet high into the air. The world's record high-jump is $6 \cdot 6 \mathrm{r}$ feet, the centre of gravity of the performer being presumably about 3 feet high at rest. He raises it therefore $3.6 \mathrm{r}$ feet into the air, from which we may calculate that the whole time occupied in the jump is about 0.96 second. All the characteristics of the proprioceptive system must be evoked in their highest degree in carrying out such a skilled, rapid, and yet violent movement in so short a time.

In long-jumping, it is well known that success consists in learning to jump high. The world's record longjump is 25.48 feet. With the check provided by the vertical impulse in the last step we cannot well imagine the horizontal velocity to be greater, at this moment, than that of roo yards completed in ro seconds; that is, than 30 feet per second. Let us assume this value, then the performer remains in the air for 0.85 second: hence we may calculate that the vertical distance covered is about 2.9 feet. Assuming the centre of gravity of the subject to have been originally 3 feet high, this means that it must have reached a height 5.9 feet in the air, enough, in a high-jump, to enable its owner to clear $5^{\circ} 9$ feet. It is interesting to find that the simple laws of mechanics emphasise so strongly the precepts of the athletic trainer.

\title{
A High-frequency Induction Furnace for making Alloys.
}

A PAPER on a high-frequency induction furnace for making alloys was presented by Mr. D. F. Campbell at the autumn meeting of the Iron and Steel Institute held in Birmingham on September ro. The early work in this field was carried out at Princetown University by Dr. Northrup, whose investigations of the physical laws governing induction from highfrequency equipment led to the evolution of the first metal-melting furnaces. As Mr. Campbell points out, low-frequency induction furnaces have been known for forty years, and twenty years ago it seemed possible that they would, to a large extent, replace the crucible process for high-grade steel making. This possibility, however, has for a variety of reasons not been fulfilled. Inductive heating has, however, found wide application in the non-ferrous trade in furnaces having a vertical slot worked on normal commercial frequencies. These furnaces have the disadvantage of requiring an iron core, in consequence of which the molten metal is contained in small channels surrounding the iron core as well as in the main bath of the furnace. This involves much wear and tear of the refractory material.

In the case of high-frequency heating the conditions

No. 2919, voL. II6] 
are quite otherwise. The container is a cylindrical vessel holding the maximum of metal with a minimum of radiating surface and refractory material exposed to corrosive action. The heat is generated in the charge to be melted and consequently there is no loss in the passage through refractory containers as in crucible furnaces. The high-frequency furnace has an immensely steep heat-gradient between the molten metal and the outside of the furnace. The furnace described by Mr. Campbell consists merely of a container or crucible placed inside a flat cylindrical coil. The intermediate space, about one inch in diameter, is filled with zircon or other insulating material contained in a silica or mica sleeve. The crucible need not be more than half an inch thick. As the heat is generated within the metal, the temperature of the crucible is very much lower than that of the metal itself. Consequently, reactions between the metal and crucible walls are reduced to a minimum, and crucibles of material quite inadmissible in other high temperature processes stand up well in the furnace.

According to the author, an ordinary clay crucible, such as is used for gold assays, will make from ro to $3^{0}$ heats of nickel-iron alloys containing less than 0.02 per cent. of carbon. A high-frequency furnace mixes the metal very thoroughly. The surface of the molten metal is pronouncedly convex, owing to the violent upward current at the centre of the liquid mass. This is a great advantage for the manufacturer of alloys made from metals which do not mix readily. The frequencies used may be termed "high" or "medium" and have varied from 20,000 to 400 periods per second, the lower figures being applicable to the larger furnaces for melting nickel silver and similar alloys. Furnaces of a capacity of $600 \mathrm{lb}$. are now. working on certain nickel alloys. In cases where it is essential that the alloys should contain a minimum of carbon, it looks as though they will have a great field of application. The author states that the capital cost of equipment is high, but that some cheapening ought to be obtained in the future.

At present the principal application of this method of heating is in the preparation of alloys which are used for the manufacture of continuously loaded cables. Indeed, the discovery of the two principal alloys now used, namely, permalloy and mumetal, was made possible by the use of a high-frequency furnace. These alloys are composed principally of nickel and iron with small percentages of other metals, and the lowest possible amount of carbon. By the use of this alloy the speed of signalling by long-distance submarine cables has been raised from a maximum of 300 letters per minute for that type of cable to 1800 for a continuously loaded cable. This performance was obtained between the Azores and the United States. An installation recently completed near Birmingham has by far the largest melting capacity of any highfrequency metallurgical works yet erected. The equipment consists of forty-two small converter units of from 35 to 40 kilo-volt ampere capacity fitted with furnaces capable of melting $20 \mathrm{lb}$. of nickel-iron alloys of the highest purity in from 40 to 45 minutes.

Great advantages are also being found for furnaces of this type used in research, owing to the speed with which small heats can be made either in vacuo or in air. The author states that in one instance where an investigation was being made into the properties of a series of alloys with a relatively high melting-point, twenty 2 -lb. heats were made in eight hours. For some time past the Metallurgical Department of the National Physical Laboratory has included in its equipment a furnace of this type, and great use is being made of it in the preparation of an exceptionally pure series of iron alloys.

\section{Obituary.}

Prof. H. H. Hildebrandsson.

$\mathrm{T}^{\mathrm{H}}$ $\mathrm{HE}$ death of Hugo Hildebrand Hildebrandsson at Upsala on July 29 of this year, at the advanced age of eighty-seven years, marks the passing of a meteorologist of exceptional character. He was secretary of the International Meteorological Committee in succession to R. H. Scott from I900 until 1907, when he himself retired from the direction of the Institute of the University of Upsala, at which he was the first professor of meteorology, to be succeeded by his son-inlaw, F. Akerblom, the present professor. His name is known throughout the meteorological world for his activity in connexion with the study of clouds in all parts of the world, which culminated in the "International Cloud Year" $1896-97$, and found further expression in the "International Cloud Atlas" published mainly under his guidance in 1896 , with a new edition in I9ro.

Hildebrandsson was scarcely less well known for his researches on "centres of action of the atmosphere" in the Transactions of the Royal Swedish Academy, and still further for his collaboration with Teisserenc de Bort, not only in the investigation of the upper air, but also in the publication through Gauthier-Villars of "Les Bases de la météorologie dynamique: Historique
-État de nos connaissances," a truly magnificent work left unfinished by the untimely death of Teisserenc de Bort: For the text of that work Hildebrandsson was mainly responsible, though it expressed the joint ambition of both to have full regard to the unity of the atmospheric circulation and treat meteoro$\log y$ as a world study. With that ambition, in 1907 , the two friends became the bureau of an International Commission for a réseau mondial. Teisserenc de Bort wished it to be telegraphic, but the expense at that time being prohibitive, Hildebrandsson pressed the claims of a climatological réseau. The Commission still exists, with Dr. Simpson as president, and in the development of wireless telegraphy Teisserenc de Bort's ambition will be realised.

It was in his attitude towards world meteorology and a réseau mondial that Hildebrandsson displayed his special characteristic. Most meteorologists are content to write commentaries on some point or subject of physical or geographical importance in the structure or circulation of the atmosphere; Hildebrandsson wanted to make out the connected story of the atmospheric circulation before embarking upon a commentary. He recognised that writing commentaries runs great risk of marking time so long as

$$
\text { No. } 2919 \text {, vol. I I 6] }
$$

